\title{
COMPARISON OF COMMERCIALLY AVAILABLE ARCHWIRES WITH NORMAL DENTAL ARCH IN A GROUP OF SAUDI POPULATION
}

\author{
Hanaa Elattar,* Alhanouf Alsulami**, Khawlah Alharbi**, Lames Alyamani*** and Lena Gary**
}

\begin{abstract}
The dental arch varies among races, population, and individuals. The principal goal of orthodontic treatment is to maintain the stability and aesthetics of the arch. It is crucial to preserve the patient's original arch form during orthodontic therapy otherwise the probability of relapse will increase.
\end{abstract}

Objectives: To determine the average dental arch form and size for Saudi adults and compare it with commercially available archwires.

Materials and methods: Dental casts of 126 Orthodontically untreated individuals with normal occlusion were obtained. For each model, the arch form was determined, the intermolar width, inter-canine width, molar depth and canine depth were measured using a digital caliper with 0.001-0.02 mm accuracy. Arch form template(Orthoform TM; 3M) was used and 9 commercially available preformed maxillary and mandibular $\mathrm{Ni}-\mathrm{Ti}$ arch wires were scanned. Measurements obtained from casts were first compared between genders, then compared with those of preformed ready-made commercially available archwires to determine which archwire has the shape that fits most accurately to the predetermined Saudi measures.

Results and Conclusion: The most common form was ovoid (48.4\%) followed by square $(30.2 \%)$ and tapered $(21.4 \%)$. No significant difference existed between male and female regarding the arch form. Comparing arch-perimeters, no significant difference existed between both gender in intercanine width \&depth as well as intermolar depth only the intermolar width showed significant difference at $(\mathrm{P} \geq 0.05)$. The most compatible archwire to the population's upper dental arch was Ortho organizer oval arch form II. While Dentaurum, Tensic-ideal arch was the most compatible archwire to the lower dental arch.

\footnotetext{
* Lecturer of orthodontics - Faculty of Dentistry- Suez Canal University /affiliated to Umm Al-Qura University, Makkah, Saudi Arabia

** Dental students at Umm Al-Qura University, Makkah, Saudi Arabia.
} 


\section{INTRODUCTION}

The dental arch is an essential element in orthodontic planning and treatment; therefore, the correct identification of dental arch form and size is necessary to achieve a stable, functional and esthetic results; otherwise, the probability of relapse will increase ${ }^{(1,2)}$.

Many years ago, great attention was given to the arch form, the Bonwell-Hawley pattern identified by Chuck GC was one of the traditional ideal arch forms that used to construct archwires ${ }^{(3)}$. Nowadays, many Diagrams were developed using a variety of mathematical formula to obtain archwires that are similar in size and form to normal dental arches and to aid orthodontist during treatment ${ }^{(4)}$. Using archwire that is incompatible with the patient's arch form will result in changes of maxillary and mandibular arch widths during orthodontic treatment ${ }^{(5)}$.Studies confirmed, periodontal breakdown, recurrence of crowding as a result of improper archwire selection if the inter-canine and inter-molar distances were notably increased ${ }^{(6)}$.

Throughout the literature, different methods were used to determine arch forms and dimensions, some of these methods were simple such as measurement of arch dimensions using caliper and subjective determination of arch form ${ }^{(7,8)}$. Nowadays, with huge development in technology and computer programs many software were used for digitization and accurate 3D construction of dental casts to achieve precise measurement of arch dimensions and accurate determination of $\operatorname{arch}_{\text {form }}^{(4,5)}$.

Many studies were done to determine the arch form and size on different populations. Lavelle et al. measured the dental arches in four major ethnic groups: Caucasians, Mongoloid, Negroid, and Australian. They concluded that there were some basic differences in dental arch size and shape between the different populations ${ }^{(9)}$. Cassidy et al. believed that the arch size and form are influenced by environmental factors more than genetic factors ${ }^{(10)}$.

Hedayati et al. compared twelve commercially available archwires with normal dental arches of the Iranian population and found that commercially available preformed archwires did not entirely cover the range of diversity of dental arch forms on their community. Most of these preformed archwires were wider than the average width. Ortho organizer archwire was the most closely matched ${ }^{(7)}$.

The aim of this study was to determine the average dental arch form and size for adult Saudi population and compare it with commercially available archwires.

\section{MATERIALS AND METHODS}

126 adults (18-30 years old) selected through convenient sampling method from several dental centers across Makkah district (western region of Saudi Arabia).

The inclusion criteria were: Orthodontically untreated individuals, Class I canine and molar relationship, Well-aligned teeth or teeth with minimal crowding, Symmetric arch, Normal vertical growth pattern; determined by clinical examination of the profile, normal overjet (1-2 $\mathrm{mm}$ ) and overbite (2-3 $\mathrm{mm}$ ). Those who have dental Class II, III canine and molar relationship, missing teeth, supernumerary teeth, anterior proximal restorations, Posterior crossbite and crowding or rotated teeth were excluded from the study. Consent forms were signed by the participants; serial numbers were used as coding for each one to protect patient confidentiality. Each participant asked to set in upright position, looking forward on the dental chair and examined clinically to ensure that each participant fulfills all the inclusion criteria. Alginate impressions were taken for each subject. Impressions were poured with dental stone within maximum half an hour to 
avoid dimensional changes. Each study model was signed by the coding number and either $\mathrm{F}$ or $\mathrm{M}$ letter $(\mathrm{F}=$ female, $\mathrm{M}=$ male $)$.

Measurments were done using a digital caliper (Neiko 01407A Stainless Steel Electronic Digital Caliper with $0.001 / 0.02 \mathrm{~mm}$. accuracy).

Two examiners were trained by an experienced orthodontist, Kappa's test was used to measure the consistency. Each examiner measured ten casts, after 15 days they repeated the measurements for the same casts to confirm the consistency. The same procedure repeated many times till we reach $95 \%$ intra-examiner consistency. For the inter-examiner consistency, the first examiner measured ten casts and the second examiner measured the same ten casts again. The same process repeated till we reach 97\% inter-examiner consistency by Kappa's test.

Nine preformed upper and lower NiTi Archwires that are commercially available in the Saudi market and commonly used by orthodontists were selected:

1. Dentaurum, Tensic-ideal arches size 0.016 Reference 766-706-00,766-707-00.

2. Dentaurum, Rematitan, ideal arch (round) Reference: 766-084-00,766-085-00.

3. Jiscop thermal trueform W3T21-240, W3T22-240.

4. Ortho organizer oval arch form II, reference 101-452,101-453.
5. Truflex full form size .018, reference 6001118,6001-018.

6. Truflex Euro form size .018, reference 5000104,5000-204.

7. TruFlex Universal Form Archwire reference 2001-104,2001-204

8. American Orthodontic natural arch form III, reference 857-704,857-714.

9. 3M unitek (3M) orthoform III (ovoid), reference 4296-916, 4296-915.

3M unitek arch forms template (oval, tapered, square) were printed on white paper to be used as a guide to determine the arch form for each subject (Figure-1). NiTi archwires were scanned using HP Deskjet 2510 scanner with a white background, the accuracy was confirmed by placing the scanned wire over the scanned photo. For each scanned archwire set (upper and lower archwires), the mean intercanine and intermolar depths of the sample were used to determine the level of the intercanine and intermolar width for each scanned archwire respectively (Figure-2,3). After measuring archwires widths (intermolar and intercanine), the mean intercanine and intermolar width of the sample were compared to the intercanine and intermolar width of each archwire, to determine which one of them mostly fits the mean of the population. The percent of compatibility were calculated manually for each wire.

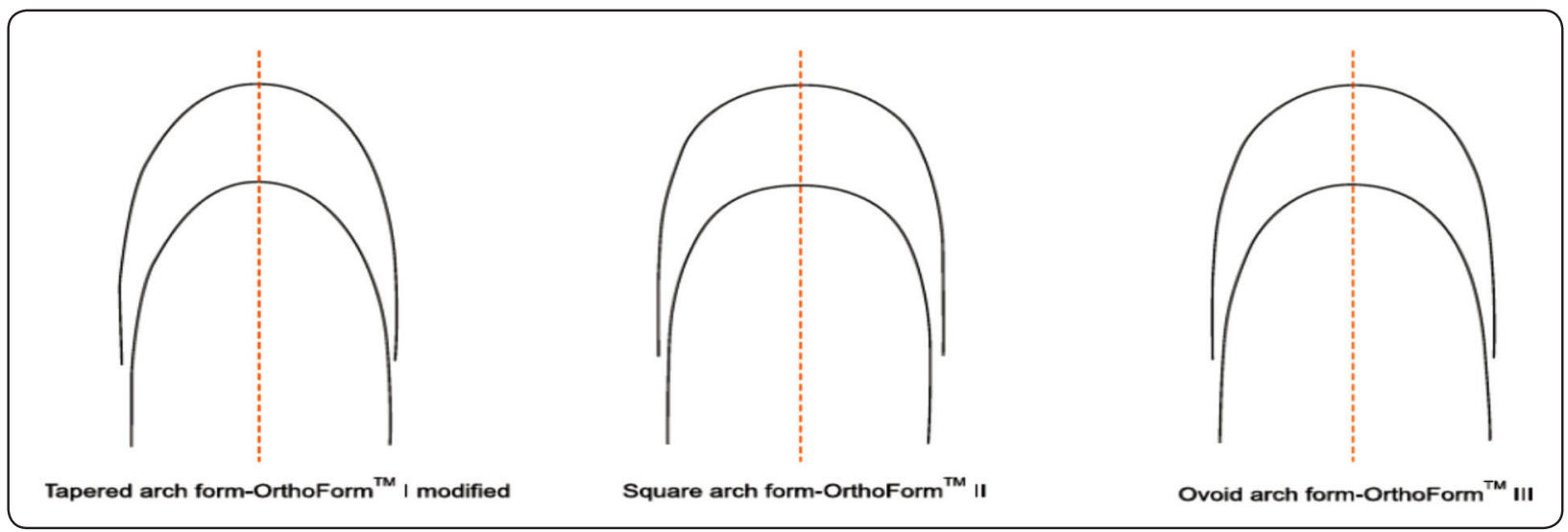

Fig. (1) Arch form templates (orthoform TM, 3M, Unitek, CA, USA) used to determine arch forms of dental arch study models 

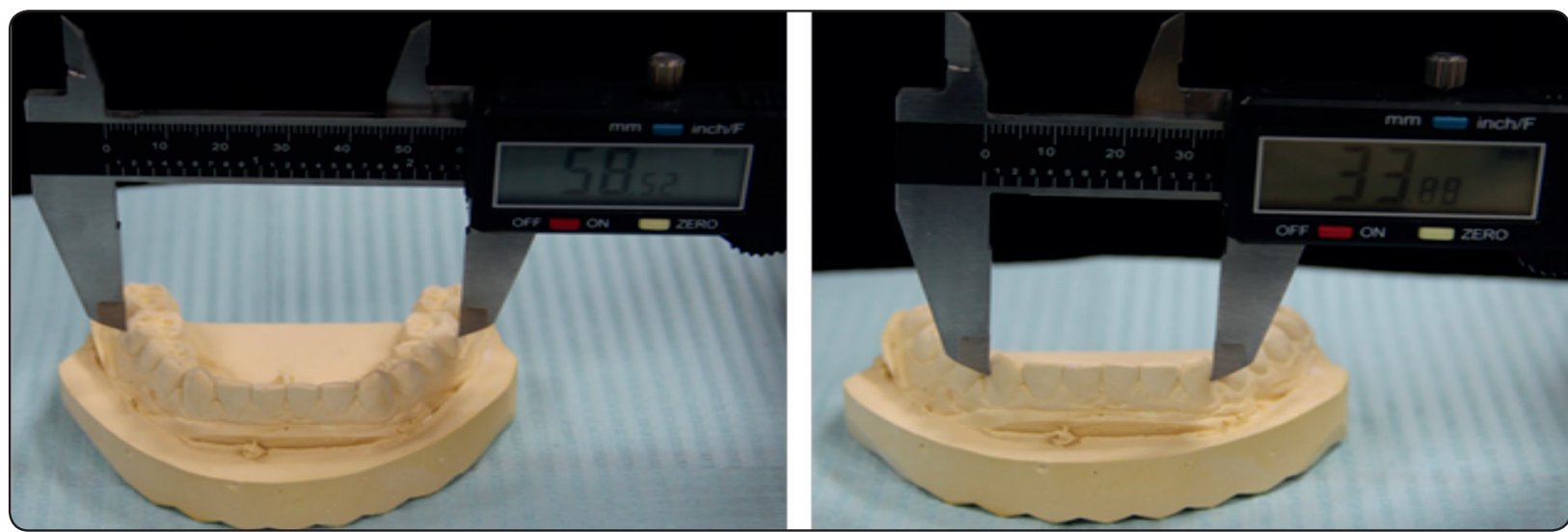

Fig. (2) A- The inter-canine width was measured from the facial axis point of canines using digital caliper. B- Also, the intermolar width were measured from the facial axis point of 1st molars using digital caliper.
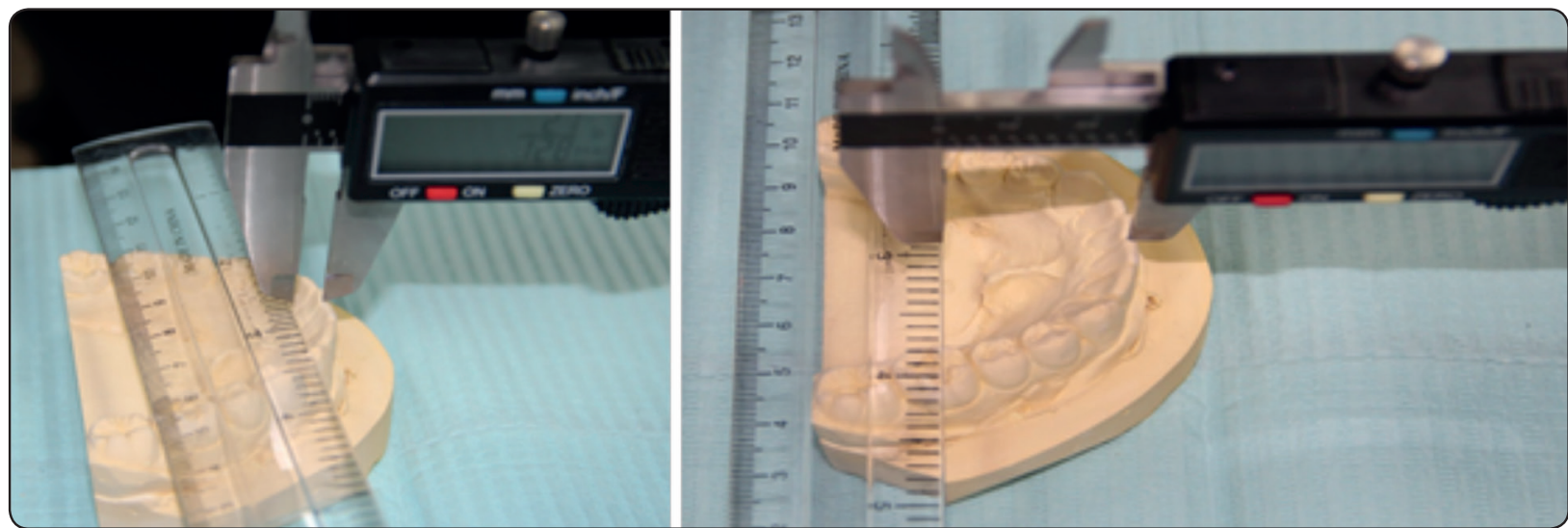

Fig. (3) Measuring the intercanine and intermolar depths. A ruler was placed on the cast representing the inter-canine width and the digital caliper measured the distance from the arch midline to the inter-canine width line. The same method was applied to determine the intermolar width for each cast

\section{STATISTICAL ANALYSIS}

Data were analyzed using IBM SPSS version Descriptive statistics was done to obtain the mean and standard deviation. T-test was used to detect the relation between arch size and sex, the level of significance was set at 0.05 (Table-1). While Chisquare test was used to find if there was a statistically significant difference between arch form and sex at $\mathrm{P}$ value 0.05(Table-2) (Figure-1). The mean and standard deviation of the sample's measurements (intercanine and intermolar width) were compared with those of the selected ready-made archwires.

\section{RESULTS}

A total of 126 subjects were included in the study almost $60 \%$ were female and $40 \%$ were male.

Comparing the mean and standard deviation of the sample's measurements (inter-canine and intermolar width and depth, male had larger arch size than female, however the difference was statistically insignificant except at the intermolar width (Table1).

There was no statistically significant difference between male and female regarding the arch form ( $>0.05$ ) (Table 2). The most common form was 
TABLE (1) Shows the mean and standard deviation of the sample's measurements (inter-canine and intermolar width and depth showing no significant difference in arch size between both genders except at the intermolar widths.

\begin{tabular}{|c|c|c|c|c|c|}
\hline \multirow{2}{*}{ With bracket } & \multicolumn{2}{|c|}{ Females } & \multicolumn{2}{|c|}{ Males } & \multirow{2}{*}{$\mathrm{t}$ (p value) } \\
\hline & Mean & $\mathrm{SD}$ & Mean & SD & \\
\hline Lower inter-canine width & 30.93 & 2.61 & 31.54 & 2.04 & $0.209(0.649)$ \\
\hline Lower inter-canine depth & 7.10 & 1.79 & 6.94 & 0.98 & $1.148(0.287)$ \\
\hline Lower inter-molar width & 50.49 & 3.91 & 52.45 & 3.20 & $5.084(0.02)_{8}$ \\
\hline Lower inter-molar depth & 24.99 & 2.05 & 26.24 & 4.46 & $2.739(0.102)$ \\
\hline Upper inter-canine width & 38.11 & 2.15 & 39.42 & 2.56 & $1.947(0.07)$ \\
\hline Upper inter-canine depth & 10.40 & 1.30 & 10.25 & 1.53 & $0.194(0.661)$ \\
\hline Upper inter-molar width & 52.84 & 7.74 & 56.17 & 4.44 & $4.439(0.03)^{*}$ \\
\hline Upper inter-molar depth & 29.14 & 2.09 & 29.13 & 1.99 & $0.000(0.989)$ \\
\hline
\end{tabular}

TABLE (2) Shows the prevalence of each arch form, Chi-square test at P value 0.05., showing no statistically significant difference between male and female regarding arch form $(\mathrm{P} \geq 0.05)$. The most common form was ovoid (48.4\%) followed by square (30.2\%) And tapered (21.4\%).

\begin{tabular}{|c|c|c|c|c|c|}
\hline \multirow{2}{*}{ Variables } & \multicolumn{3}{|c|}{ Arch form } & \multirow{2}{*}{$\begin{array}{c}\text { Total } \\
\mathrm{N}(\%)\end{array}$} & $\begin{array}{c}\text { Chi square } \\
(\mathrm{p} \text { value })\end{array}$ \\
\cline { 2 - 5 } & Ovoid & Tapered & Square & $\mathrm{N}(\%)$ & \\
\cline { 2 - 5 } & $\mathrm{N}(\%)$ & $\mathrm{N}(\%)$ & $14(28.3 \%)$ & $50(100 \%)$ & $22.231(0.000)^{*}$ \\
\hline Females & $22(43.5 \%)$ & $13(17.2 \%)$ & $24(31.0 \%)$ & $76(100 \%)$ & $26.653(0.000)^{*}$ \\
\hline Males & $39(51.7 \%)$ & $27(21.4 \%)$ & $38(30.2 \%)$ & $126(100 \%)$ & $24.709(0.000)^{*}$ \\
\hline Total & $61(48.4 \%)$ & \multicolumn{3}{|c|}{$1.206(0.547)$} \\
\hline Chi (p value) & \multicolumn{5}{|c|}{} \\
\hline
\end{tabular}

ovoid $(48.4 \%)$ followed by square $(30.2 \%)$ and tapered (21.4\%) (Table 2, Figure 4).

The mean of the arch size of the whole sample was used in our study to be compared with the archwires width. The mean intercanine distance in the upper arch was $38.62 \pm 2.8 \mathrm{~mm}$; whereas in the lower arch the results were $31.17 \pm 2.4 \mathrm{~mm}$, (Table 3).

The most compatible archwire to the population's upper dental arch was the Orthoorganizer oval arch form II. While Dentaurum, Tensic-ideal arche was the most compatible archwire to the lower dental arch. (Figure 5).
TABLE (3) Shows the mean and standard deviation of the sample's measurements (intercanine width and depth)

\begin{tabular}{|l|l|l|}
\hline & Mean & Std. Deviation \\
\hline $\begin{array}{l}\text { Lower inter-canine depth } \\
\text { +brackets }\end{array}$ & 7.0429 & 1.52423 \\
\hline $\begin{array}{l}\text { Lower inter-canine width } \\
\text { +brackets }\end{array}$ & 3.169 & 2.41240 \\
\hline $\begin{array}{l}\text { Upper inter-canine depth + } \\
\text { brackets }\end{array}$ & 38.623 & 2.83827 \\
\hline $\begin{array}{l}\text { Upper inter-canine width }+ \\
\text { brackets }\end{array}$ & 10.345 & 1.39104 \\
\hline
\end{tabular}




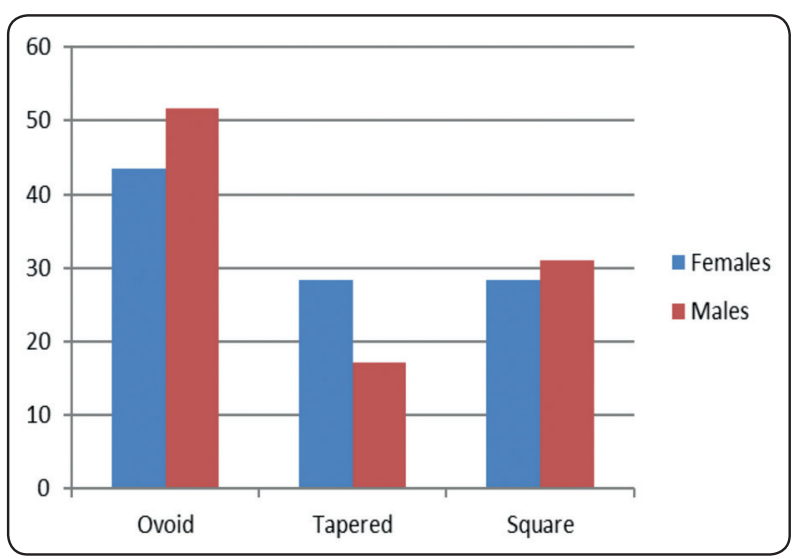

Figure (4) the prevalence of each arch form in both genders

\section{DISCUSION}

Our study is a cross-sectional study that was conducted to calculate the average dental arch form and size for adults' Saudi population and detect the arch form and size that best match the population norms among all orthodontic archwires available in the Saudi market. Identification of dental arch form and size before orthodontic treatment is acritical element in the selection of the archwire; to achieve a stable, functional and esthetic results otherwise, the risk of relapse will increase ${ }^{(5)}$. Identifying the most common arch form and average dental arch size in a certain population is important as it will help constructing archwires that mostly fit the arch form and size of that population. Most of archwires that orthodontists use were designed for American and European population $^{(7)}$, this study was conducted on Saudi population in the western region of KSA to determine which of the commercially available NiTi archwires mostly fit the population in Saudi Arabia.

Previous studies showed that the dental arch width changes rapidly with age. Arch width rapidly increases especially during the mixed dentition ${ }^{(11)}$. Results of average arch-width changes after the eruption of the second molars were varied, Moorrees reported arch width was constant ${ }^{(11)}$, increased

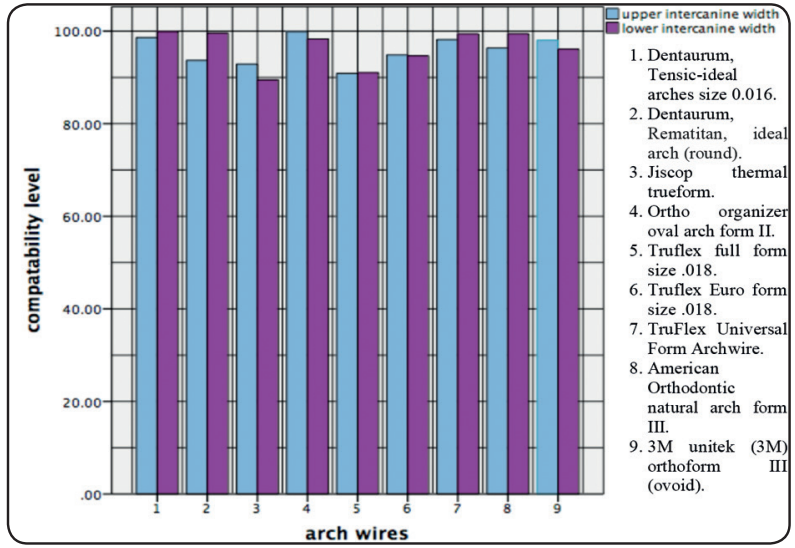

Figure (5) shows different archwires and their compatibility level to the mean of the population at the lower and upper intercanine width

for male and decreased for female subjects as stated by $\mathrm{Knott}^{(12)}$, decreased for all subjects as reported by Sinclair and Little ${ }^{(13)}$, and did not change or decreased slightly, as negligible changes in arch width occurs during adolescence (smaller than $1 \mathrm{~mm}$ ) (Bishara etal 1994) ${ }^{(14)}$. According to (Oda et al. 2010) the arch size and form reaches the maximum growth with minimal changes at the adolescence period $^{(15)}$. In our study the selected age group was 18-30 years old, in such age group changes in the arch size are negligible. Therefore, the adult dental arches used in this study were adequately selected.

It is necessary to consider the variation of bracket thicknesses to analyze the transverse relationship between tooth surfaces and archwires ${ }^{(16,17)}$. Therefore, in this study, the mean values of bracket thicknesses of popular products were added to the mean of all measurements to simulate the clinical situation and used to evaluate the general relationship between variation of archwire forms and normal diversity of dental occlusion. This method was helpful in analyzing the influence of bracket thickness during archwire width evaluation without damaging the dental casts by placement of many sets of brackets ${ }^{(15)}$

During the initial phase of orthodontic treatment elastic alloy archwires such as NiTi archwire 
usually are used for leveling and alignment of teeth. Most Orthodontists use oval shape archwire as a standard for all the patients ${ }^{(4)}$. This is ideally not correct because it will lead to relapse, the original arch form should be preserved to ensure long-term stability of orthodontic treatment ${ }^{(5,7)}$. The arch form has many classifications, however, Bayome et al. found no clinically significant difference between dividing dental arches into five arch forms instead of three arch forms. They recommended the classification based on three major arch forms better for clinical applications ${ }^{(18)}$. in our study we used the most common classification: tapered, ovoid, and square $\operatorname{arch}$ forms ${ }^{(19)}$.

There are different arch forms in every population. The most prevalent arch form and size of different ethnicities should be considered when selecting arch wires because the industry manufactures arch wires according to the normal dental arch size and shape of a special population ${ }^{(7)}$. Vietnamese population had the square arch form as the most distributed arch form then ovoid and lastly tapered ${ }^{(5)}$, For Korean people, the most frequent arch form is square $^{(20)}$ Tapered arch form was the most common arch type among Malaysians ${ }^{(19)}$ and Turkish ${ }^{(5)}$. The most prevalent arch form in our sample was ovoid (48.4\%), followed by square (30.2\%), and tapered (21.4\%). The ovoid arch form was commonest arch form on Israeli population ${ }^{(21)}$. In our study no statistically significant difference excited between both genders, which is similar to the results found by Paranhos et al. on Caucasian individuals ${ }^{(4)}$. Angle stated that the difference in arch forms can be attributed to many factors including race, type, and temperament ${ }^{(3)}$.

Comparing male to female arch perimeters, we found significant difference in the intermolar width but no significance existed between both gender in intercanine width \&depth as well as intermolar depth. Our results were different from studies conducted previously, it may be attributed to variation in the ethnic backgrounds and sampling size. Prasad et al. found that male arch widths were significantly larger than those of females $(\mathrm{P}<0.05)$ in untreated adult South Indian population, they compared their results with studies done in other population and concluded that the dental arch width varies according to many factors including gender and race $^{(6)}$. Raberin et al. related size to sex; which was smaller in female as compared to male, while the mandibular arch form was not related to the $\operatorname{sex}^{(22)}$. Many studies found that male arch widths were significantly larger than females arch widths and men have wider and deeper arches than women ${ }^{(23,24,25,26)}$.

Since we found that there was no statistically significant difference in the intercanine width and depth in our sample which are the most important measurements used during archwire selection ${ }^{(27,28)}$, the mean of the arch size of the whole sample was used in our study to be compared with the archwires width. The most compatible preformed archwires to the normal Japanese dental arch forms were the Orthos (Ormco, Glendora, Calif) and Vari-Simplex large (Ormco) types ${ }^{(15)}$. Roth small" (index value 1.556) and "Ideal Form Medium" (index value 0.645) arch wires were better fit to both arches in the Caucasian, while "Damon" (index value 1.447) and "Ideal Form Large" (index value 1.695) fitted better to the size and shape of both arches in the African $^{(29)}$. On Iranian population, Ortho organizer arch wire was the most closely matched ${ }^{(7)}$. In our study, we found that the most compatible archwire to the population's upper dental arch was Ortho organizer oval arch form II. and Dentaurum, Tensicideal arch was the most compatible archwire to the lower dental arch.

In spite of the availability of variety of arch wire brands in the Saudi market, only a few can be used safely to avoid post treatment relapse. These facts recommend that Orthodontists pre-checking of arch wire is necessary for prevention of side effects of arch wires with inappropriate width. Arch shape 
and arch widths in patients with Class III, Class II, long face, short face tendency, extraction cases with severe crowding are all different from the normal population. Thus, further studies are needed to compare preformed arch wires with these patients ${ }^{(30,31)}$.

\section{ETHICAL STATEMENT}

This study was done in full accordance with the ethical principles of the Umm Al-Qura University, Faculty of Dentistry, Makkah Saudi Arabia.

\section{REFERENCES}

1. Bayome M, Sameshima GT, Kim Y, Nojima K, Baek SH \& Kook YA: Comparison of arch forms between Egyptian and North American white populations. Am J Orthod Dentofacial Orthop. 2011 Mar; 139(3).

2. Celebi AA, Keklik H, Tan E\& Ucar FI: Comparison of arch forms between Turkish and North American Dental Press J Orthod. 2016 Mar-Apr; 21(2), 51-58.

3. Chuck GC: Ideal arch form. Angle orthod. $1934 ; 4: 312-27$ (Cited)

4. Paranhos LR, Andrews WA, Joias RP, Berzin F, Junior ED\& Trivino T: Dental arch morphology in normal occlusion. Braz J Oral Sci. 2011 May; 9(4):475-80.

5. Taner TU, Ciger S, El H, Germeç D \& Es A: Evaluation of dental arch width and form changes after orthodontic treatment and retention with a new computerized method. Am J Orthod Dentofacial Orthop 2004; 126: 64-75.

6. Prasad M, Kannampallil ST, Talapaneni AK, George SA \& Shetty SK: Evaluation of arch width variations among different skeletal patterns in South Indian population. Journal of Natural Science, Biology and Medicine 2013, 4(1), 94-102.

7. Hedayati Z, Fakhri F, \& Gosha VM: Comparison of Commercially Available ArchWires with Normal Dental Arch in a Group of Iranian Population. J Dent Shiraz Univ Med Sci., 2015; 16(2), 106-12.

8. Padilla M, Tello L, Moreno F, Osorio JC \& Bedoya A Analysis of dental arch dimensions in three Colombian ethnic groups. Int. J. Morphol. 2013, 31(1):100-106.

9. Lavelle CL, Foster TD, Flinn RM: Dental arches in various ethnic groups. Angle Orthod.,1971; 41, 293-99.
10. Cassidy KM, Harris EF, Tolley EA, Keim RG. Genetic influence on dental arch form in orthodontic patients. Angle Orthod. 1998; 68, 445-54.

11. Moorrees CFA. The dentition of the growing child. Cambridge, Mass: Harvard University Press; 1959

12. Knott VB. Size and form of the dental arches in children with good occlusion studied longitudinally from age 9 years to late adolescence. Am J Phys Anthropol 1961;19:263-84

13. Sinclair PM, Little RM. Maturation of untreated normal occlusion. Am J Orthod 1983;83:114-23.

14. Bishara SE, Treder JE, Jakobsen JR. Facial and dental changes in adulthood. Am J Orthod Dentofacial Orthop 1994;106:175-86

15. Oda S, Arai K, Nakahara R: Commercially available archwire forms compared with normal dental arch forms in a Japanese population. Am J Orthod Dentofacial Orthop. 2010; 137 (4), 520-27.

16. Braun S, Hnat WP, Leschinsky R \& Legan HL: An evaluation of the shape of some popular nickel titanium alloy preformed arch wires. Am J Orthod Dentofacial Orthop.1999; $116,1-12$.

17. Knox J, Jones M, Durning P. An ideal preformed archwire. Am J Orthod 1993;20:65-70.

18. Bayome M, Han SH, Choi JH, Kim SH, Baek SH, Kim DJ, et al. New clinical classification of dental arch form using facial axis points derived from three-dimensional models. Aust Orthod J 2011; 27: 117-124

19. Othman SA, Xinwei ES, Lim SY, Jamaludin M, Mohamed $\mathrm{NH}$, Yusof ZY and Hussein NN. Comparison of arch form between ethnic Malays and Malaysian Aborigines in Peninsular Malaysia Korean J Orthod. 2012; 42(1), 47.

20. Kook YA, Nojima K, Moon HB, McLaughlin RP, Sinclair PM. Comparison of arch forms between Korean and North American white populations. Am J Orthod Dentofacial Orthop 2004; 126: 680-686.

21. Gafni Y, Tzur-Gadassi L, Nojima K, Mclaughlin RP, Abed Y, \& Redlich M: Comparison of arch forms between Israeli and North American white populations. Am J Orthod Dentofacial Orthop. 2011; 139(3), 339-44.

22. Raberin M, Laumon, B, Jean-Louis M and Brunner F: Dimensions and form of dental arches with normal occlusions. Am J Orthod Dentofacial Orthop. 1993; 104(1) $67-72$ 
23. Olmez S and Dogan S: Comparison of the arch forms and dimensions in various malocclusions of the Turkish population. OJST. 2011, 1, 158-64.

24. Bhowmik SG, Hazare PV\& Bhowmik H: Correlation of the arch forms of male and female subjects with those of preformed rectangular nickel-titanium archwires. Am J Orthod Dentofacial Orthop.2012; 142(3), 364-73.

25. Patel VJ, Bhatia AF, Mahadevia SM, Italia S \& Vaghamsi M: Dental Arch Form Analysis in Gujarati Males and Female having normal occlusion. J Indian Orthod Soc.2012; 46(4), 295-99.

26. Padilla M, Tello L, Moreno F, Osorio JC \& Bedoya A. Analysis of dental arch dimensions in three Colombian ethnic groups. Int. J. Morphol. 2013, 31(1):100-106.

27. McNamara C, Karen J, Drage K, Jonathan R, Sandy J , Anthony J. An evaluation of clinicians' choices when se- lecting archwires. European Journal of Orthodontics 32 (2010) 54-59.

28. Silveira A.M, Burke, S.P.; Van Stewart, A.; Goldsmith, L.J.; Yancey, J.M.; Scarfe, W.C. Angle Orthodontist, February 1998, A meta-analysis of mandibular intercanine width in treatment and postretention. Angle Orthodontist $68: 53-60$

29. Lombardo L, Coppola P, Siciliani G: Comparison of dental and alveolar arch forms between different ethnic groups. Int Orthod_2015, 13(4), Pages 462-88.

30. Uysal T, Memili B, Usumez S, Sari Z. Dental and alveolar arch widths in normal occlusion, class II division 1 and class II division 2. Angle Orthod 2005; 75: 941-947.

31. Uysal T, Usumez S, Memili B, Sari Z. Dental and alveolar arch widths in normal occlusion and Class III malocclusion. Angle Orthod 2005; 75: 809-813. 